\title{
TEMP Regimen
}

National Cancer Institute

\section{Source}

National Cancer Institute. TEMP Regimen. NCI Thesaurus. Code C10136.

A chemotherapy regimen consisting of tamoxifen, etoposide, mitoxantrone, and cisplatin that may be used in the treatment of breast cancer. 